\section{Covid-19: Reassess effects of mandatory vaccination on staffing, urge unions}

Adele Waters

Healthcare unions are urging the government to carry out an updated impact assessment on how its policy of mandatory covid-19 vaccination for healthcare workers in England will affect staffing numbers.

They warned that the new rules, which require all patient facing staff to be fully vaccinated by 1 April 2022, ${ }^{1}$ risk worsening the staffing crisis and could undermine the NHS's ability to provide care at a time of great pressure. ${ }^{2}$ They also condemned the prospect of managers being forced to sack staff who are unwilling to get vaccinated rather than redeploy them.

The BMA said that the policy may need to be delayed if "services will be left untenable, and patients put further at risk."

The criticism came after NHS England issued guidance last week ordering employers to begin implementing the policy from this week. ${ }^{3}$

The new rules apply across primary and secondary care in the NHS and the independent health sector. They provide a 12 week grace period (from 6 January) to allow unvaccinated staff to have had their first dose by 3 February 2022, so as to have received their second dose by the deadline. After that, employers will no longer be able to deploy patient facing workers who cannot prove they are fully vaccinated (unless they are exempt). This includes bank and agency workers, locums, students, and trainees. Unvaccinated employees will face dismissal from their roles.

In November the Department of Health and Social Care's impact assessment found that as many as 73 ooo NHS staff in England could lose their jobs as a result of the policy. 4

Although the BMA supported covid vaccinations for staff, it said it was "very worrying" to see that managers were under no obligation to consider redeployment of unvaccinated staff, protect the pay of those who are redeployed, or give severance pay to staff who are dismissed as a result of being unvaccinated.

A BMA spokesperson said, "The NHS does have a duty to NHS staff, who have been instrumental in keeping patient services running throughout the pandemic, and considering redeployment should be an absolute requirement given how seriously staff shortages are already affecting the NHS."

Longstanding shortages in the health service-the NHS in England currently has 99000 vacancies-have been made far worse by the rapid spread of omicron, the spokesperson said. Absences because of covid illness or isolation rose by $63 \%$ in England's acute care hospital trusts in the two weeks to 9 January, while more than 81000 staff were off sick for all reasons.

"The staff working in the NHS are its most precious asset, and to terminate their employment unnecessarily, when other options like redeployment might be available, is an unnecessary waste of their skills and expertise," said the BMA spokesperson.

The Doctors' Association UK is calling for a moratorium on mandatory vaccination, followed by an urgent review of current staffing levels and their implications for patient safety.

"Allowing a proper impact assessment is a responsible way forward," said its chair, Jenny Vaughan. "Any reassurance gained for the public about staff presenting less of a risk because 'only' vaccinated staff will be treating them is easily offset by the added pressures this mandate will cause to an already buckling NHS."

The Royal College of Nursing has said it, too, had major concerns about making vaccinating mandatory because it could marginalise people who were vaccine hesitant and put further pressure on a hugely depleted workforce. It backed the call for an updated risk assessment. Pat Cullen, its general secretary and chief executive, said, "We are calling on the government to recognise this risk and delay a move which by its own calculations looks to backfire. To dismiss valued nursing staff during this crisis would be an act of self-sabotage."

Though supportive of the policy, NHS trust leaders are concerned about its rollout and potential effect on staffing levels. King's College Hospital NHS Foundation Trust, for example, has predicted that the policy could reduce its workforce by $10 \%$, given that 14000 staff remained unvaccinated.

Saffron Cordery, deputy chief executive of NHS Providers, said, "Trust leaders will continue to do everything they can to support vaccine hesitant staff while managing the significant risks presented by this policy in the coming weeks.

"No trust leader remotely relishes the prospect of dismissing their staff, but they are obliged to implement the law."

Several recruitment agencies contacted by The BMJ said they were concerned about the effect of the policy on their ability to place staff, as well as the additional bureaucratic burden in terms of processing documentation-taking around 45 minutes per locum.

Adam Parrish, managing director of Pertemps, a Coventry based national agency, said, "In terms of numbers, we believe that we have an uptake of the vaccine of around 90\%, which is consistent with the 
published NHS data. We are concerned that there is not a strong contingency plan within the NHS to cope with the inevitable reduction in the medical workforce after 1 April.”

Currently, there are no plans to introduce mandatory vaccination for healthcare staff elsewhere in the UK. However, employees working for organisations that provide services in England as well as any devolved nation will need to comply with the new rules.

1 Rimmer A. Covid vaccination to be mandatory for NHS staff in England from spring 2022. BMJ 2021;375:n2733. doi: 10.1136/bmj.n2733 pmid: 34758984

2 Torjesen I. Covid-19: Many hospitals "are not declaring critical incidents" despite severe pressures. BMJ2022;376:060. doi: 10.1136/bmj.060 pmid: 35017222

3 England NHS, Improvement NHS. Vaccination as a condition of deployment (VCOD) for healthcare workers: Phase 2-VCOD implementation. Jan 2022. https://www.england.nhs.uk/coronavirus/publication/vcod-for-healthcare-workers-phase-2.

4 Department of Health and Social Care. Impact statement: making vaccination a condition of deployment in health and wider social care sector. Nov 2021. https://assets.publishing.service.gov.uk/government/uploads/system/uploads/attachment_data/file/1032255/making-vaccination-a-condition-of-deployment-in-the-health-and-wider-social-care-sector-impact_statement.pdf.

This article is made freely available for personal use in accordance with BMJ's website terms and conditions for the duration of the covid-19 pandemic or until otherwise determined by BMJ. You may download and print the article for any lawful, non-commercial purpose (including text and data mining) provided that all copyright notices and trade marks are retained. 